\title{
Within All This Can Happen: Artefact, Hypermediacy, and W. G. Sebald
}

Jürgen Simpson, University of Limerick

\begin{abstract}
All This Can Happen, by David Hinton and Siobhan Davies, is a film based on a novella by Robert Walser, a writer who owned little, possessed no books, and invariably wrote on second-hand paper. The film's integration of similarly borrowed materials and the nature of interactions between image, text, and sound are the central focus in this article which draws upon the work of W.G. Sebald and the vibrant field of related study as a means of analysis and enquiry. It specifically explores All This Can Happen's embrace of archival conditions and decay, the interaction between fictive and authentic layers, and how complex hypermediated visual structures are facilitated by both the text's grounding effect and its thematic focus on the act of walking.
\end{abstract}

Keywords: postdigital, aesthetics, archive, artefact, screendance, Sebald, Bolter and Grusin, hypermediacy, Walser, Barthes, photo-filmic, audio-visual, sound design, Chion, voiceover, decay, Cascone

All This Can Happen, by David Hinton and Siobhan Davies, ${ }^{1}$ is a film based on a novella by Robert Walser, a writer who owned little, possessed no books and invariably wrote on second-hand paper. This film's integration of similarly borrowed materials and the nature of interactions between image, text and sound are the central focus in the following essay which draws upon the work of W.G. Sebald and the vibrant field of related study as a means of analysis and enquiry.

Der Spaziergang (The Walk) by Robert Walser, whose fine writings and influence on contemporaries such as Hermann Hesse and Franz Kafka could not prevent a dwindling career and madness, is a text that presents an innocent wonder with an undercurrent of strangeness. ${ }^{2}$ Walter Benjamin describes the "unusual delicacy" that is readily available in Walser's work as hiding a layer devoid of worldly ambition: "the pure and animated spirit of convalescent life." ${ }^{3}$ This characteristic self-effacement, a writing in which content vies precariously with the medium itself, is described by Benjamin: "Everything seems lost to him, a gush of words comes pouring out in which each sentence has the sole purpose of rendering the previous one forgotten." ${ }^{4}$ So it is in The Walk, where the narrator describes a journey through town and country, and lingers at every turn on that which is encountered. Person or animal, hat or dress, air or 
light; the opportunity for wonder is offered equally by all things, and each thing plays its part in The Walk's descriptive footfall. The effect is an unfolding in which each present moment, once described, is displaced by the next. The result is a narrative topology that is reduced in its directionality, its temporal forms flattened out into sequences of moments that, exhausted by detail, sustain the present.

Robert Walser's initial impact on the literary and social scene during the early part of the 20th century was followed by a gradual retreat into obscurity culminating in a quarter century spent in mental institutions. His death on Christmas Day 1956, his body frozen in the snow discovered by children, sparked a slow rise in recognition. Amongst those who championed his work were J.M Coetzee, ${ }^{5}$ Susan Sontag, and W.G. Sebald. ${ }^{6}$ Sebald's relationship went beyond admiration and entered into the realm of the uncanny, for Sebald saw in Walser a familial kinship and noted these in a chapter devoted to him in his 1998 book Logis in einem Landhaus: Über Gottfried Keller, Johann Peter Hebel, Robert Walser und Andere (A Place in the Country). ${ }^{7}$ The sensitivity to coincidence that enabled this kinship is located throughout Sebald's writing and with this receptiveness retained, I would like to implement aspects of Sebald's approach as a key to engaging with the film All This Can Happen. It is specifically through Sebald's application of photography and his embrace of the archive that we may engage with the nature of interactions between text, image, and sound in All This Can Happen. The significant scope of discussion dedicated to Sebald resonates with All This Can Happen, and can offer a range of access points from which to engage with the film and this existing body of work.

"Seen as live evidence, the photograph cannot fail to designate, outside of itself, the death of the referent, the accomplished past, the suspension of time. And seen as deadening artefact, the photograph indicates that life outside continues, time flows by, and the captured object has slipped away". ${ }^{8}$ These opinions by Thierry de Duve are indicative of the position held by many of those who have addressed photography's tentative relationship with time. Susan Sontag states that "photography is the inventory of mortality," ${ }^{\prime 9}$ and much of Roland Barthes' final work Camera Lucida is intent on deciphering the photograph as an indicator of mortality. ${ }^{10}$ This relationship between memory and photography is particularly significant in the context of Sebald's work. Maya Barzilai argues that, "the manner in which Sebald embeds old black-andwhite photographs with the different narratives not only encourages a comparison between memory and photography, but also allows the reader to gain, experientially, a sense of the disruptive effect of the belated return of the past."11 Of additional significance is the manner in which Sebald integrates the uncaptioned image within the text: The line between documentation and fiction is obscured and the inclusion of visual "evidence" presents the reader with concrete points of navigation which simultaneously support and obstruct the mind's eye. Of course, these discussions are specific to the still-image and some, including Barthes, ${ }^{12}$ have argued successfully that 
the fluidity of the moving-image liberates it from the melancholy of the photograph. This may at first appear to hinder a direct engagement between Sebald's text/image interplay and the nature of temporalities within All This Can Happen. However, although the latter is a film, I suggest that much of its imagery does not function in a traditionally filmic manner, and that this position plays an important role in understanding the manner in which sound, image, and text interconnect. There are a variety of reasons that support this position but in short, their cumulative effect is to evolve and dissect the absolute and binary opposition presented by Barthes. These arguments for differentiation can be broken down into two strands: the mechanisms of presentation and the nature of the audio-visual materials used.

A discussion of these mechanisms requires an initial statement as to the nature of the traditional filmic experience as follows: traditional film engages a desire for an illusion in which the viewer is presented with a single window-like frame through which a spatially and temporally realistic moving image is constructed. The result aspires toward a condition that has been described by Bolter and Grusin as "transparent immediacy,"13 and its acquisition has been the preoccupation of painters and writers for many centuries. The rationale behind transparent immediacy is to hide the mechanisms at play "by ignoring or denying the presence of the medium and the act of mediation" and thereby foregrounding the illusion presented. ${ }^{14}$ Photography and classical cinema adopted this realist inheritance directly from the mathematically induced naturalism originating in the Quattrocentro, yet both technologies are contrasting in their effectiveness at conveying an illusion in which the mechanisms of production are hidden. It is this contrast that is implicit in Barthes' binary juxtaposition between photography and film. In Camera Lucida, Barthes states, "Like the real world, the filmic world is sustained by the presumption that, as Husserl says, 'the experience will constantly flow by in the same constitutive style,' but the Photograph breaks the 'constitutive style' (that is its astonishment); it is without future." 15 This bringing to life of the image, by providing it with a future unfolding frame by frame, disguises its operational genesis and enables a form of transparent immediacy unavailable to the still photograph. Time unfolding in film defies analysis of the individual moment and offers an illusion approaching that of our own visual and sonic experience.

However, All This Can Happen does not conform to these paradigms and instead adopts a range of strategies that engage an attitude of self-reflexivity by deliberately disrupting the perceptual effect of the moving-image illusion. Of particular note is the strategy of "hypermediacy," coined by Bolter and Grusin, which they describe as follows:

If the logic of immediacy leads one either to erase or to render automatic the act of representation, the logic of hypermediacy acknowledges multiple acts of representation and makes them visible. Where immediacy suggests a unified visual space, contemporary hypermediacy offers a 
heterogeneous space, in which representation is conceived of not as a window on to the world, but rather as "windowed" itself-with windows that open on to other representations or other media. The logic of hypermediacy multiplies the signs of mediation and in this way tries to reproduce the rich sensorium of human experience. ${ }^{16}$

If filmic immediacy can be achieved by an adherence to photorealistic paradigms within a regular temporal progression, then All This Can Happen's mode of presentation offers up a very different experience. Formed entirely from archival materials from film's inaugural period using black-and-white footage, All This Can Happen introduces two mechanisms within its first ten seconds that render "immediate" viewing impossible. The first mechanism is the application of a time distortion in which a group of film frames are looped repeatedly. Whilst the loop point is not explicit, the result frustrates the fundamental temporal principle of the film, which is replaced by an agitated repetition formed from the limited movement within those frames. The second mechanism is the sudden cessation of movement, whereupon the rolling film alights on a single frame and takes on the form of a static photograph. Again the perceptual effect is of an interruption to the progression of filmic time. Both of these techniques, which reoccur throughout All This Can Happen, cause a collapse of any continuous objective realism by refuting the inherent flow of time that passes from one frame to the next. This collapse in turn enables a close engagement with the forms of photographic and textual interplay that occur in the W.G. Sebald's work. Furthermore, the technologies that enable these forms of assemblage are mostly specific to the non-linear editing technologies of the digital age and therefore alien to the footage being manipulated. These mechanisms, along with the use of overtly archival materials distinct from the digital editing, further disable the possibility of filmic immediacy and partially return the images to their points of origin in the past. Indeed, it is mechanisms such as these that have enabled what Streitberger and van Gelder define as "photo-filmic images,"17

based on the insight that the ontological difference between film and photography, usually claimed by scholars of photography theory and film studies up to the 1990's, no longer holds in the digital era. With the advent of digital technology, the boundaries between the photographic and the filmic image are constantly blurred, both technically [...] and perceptively -in leaving the spectator in doubt of the (photographic or filmic) nature of the image. ${ }^{18}$

In Death 24x a Second - Stillness and the Moving Image, Laura Mulvey describes the perceptual outcome that results when conditions such as those found in All This Can Happen are met: 
Of particular interest is the relation between the old and the new, that is, the effect of new technologies on cinema that has now aged. Consciousness of the passing of time affects what is seen on the screen: that sense of a "sea-change" as death overwhelms the photographed subject affects the moving as well as the still image. There is, perhaps, a different kind of voyeurism at stake when the future looks back with greedy fascination at the past and details suddenly lose their marginal status and acquire the aura that passing time bequeaths to the most ordinary objects. The "aesthetics of delay" revolve around the process of stilling the film but also repetition, the return to certain moments or sequences, as well as slowing down the illusion of natural movement. The delayed cinema makes visible its materiality and its aesthetic attributes, but also engages an element of play and of repetition compulsion. ${ }^{19}$

Although a fragmentation of film's temporal dynamic displaces 'immediate' viewing and, paradoxically, exposes its time of registration, it is the nature of the audio-visual materials used that firmly locates All This Can Happen's imagery in the past and which enable a particularly effective encounter with Sebald's embrace of archive and memory. Hinton and Davies' choice to construct their work entirely from archival footage is arguably the work's most striking feature, and the specific qualities of these materials will be discussed shortly. However, behind the overt archival nature of these materials lies a deeper integration of archival practices and viewing strategies that significantly informs the structural and metaphorical qualities of this work. Analogous positions featured throughout Sebald's work are particularly enlightening in exploring the capacities of the archive beyond the initial level of pictorial manifestation. In Sebald, we find a distinctive embrace of the archive that appears continuously in the structural forms of the text, in its themes, and as a mechanism for correlation and arrangement. ${ }^{20}$ In his book W. G. Sebald: Image, Archive, Modernity, J.J. Long delves deeply into Sebald's explorations of archive and reveals a wide range of strategies that build directly on archival models and modes of presentation. Whilst this survey's embrace is far reaching, many of its insights have the potential to illuminate similar mechanisms and perceptual strategies in All This Can Happen-and by extension within other digital presentation modes.

One such insight is revealed by examining the form of hypermediacy considered by Bolter and Grusin to be most prevalent in contemporary digital media: "the heterogeneous 'windowed style' of World Wide Web pages, the desktop interface, multimedia programs, and video games." ${ }^{21}$ Such systems of organisation are found throughout All This Can Happen where the "windows within windows" fragmentation of the screen is a central formal strategy. The arrangement of panes present images in a display of correlation and counterpoint that continuously shifts the screen's subdivision and geometric form. That this malleability of shape and manner of 
fragmentation finds its likeness not in the static arrangement of classical cinema but in the windows-type interface of the computer is clear from Bolter and Grusin's description of the latter:

Unlike a perspective painting or three-dimensional computer graphic, this windowed interface does not attempt to unify the space around any one point of view [...] Windows may change scale quickly and radically, expanding to fill the screen or shrinking to the size of an icon. And unlike the painting or computer graphic, the desktop interface does not erase itself. The multiplicity of windows and the heterogeneity of their contents mean that the user is repeatedly brought back into contact with the interface, which she learns to read just as she would read any hypertext. ${ }^{22}$

It is this hypermediated arrangement of the film's materials, in conjunction with their photo-filmic quality, that enables a correlation with Sebald's preoccupation with archive and display and reveals a transformation that Long describes as a "process of decontextualisation and recontextualisation". ${ }^{23}$ Christina Kraenzle illustrates how Sebald emphasises "how the photographer is also a kind of collector, searching for and creating meaning in individual decisions regarding selection, framing, and composition, acts that are later mirrored in the amassing, sifting through, and arrangement of individual photographs to be displayed in the photo album." ${ }^{24}$ The ramifications of such arrangements are of particular note here; the presentation of diverse images (or indeed objects) within a unified space (such as a curio cabinet or photo album) enforces a homogeneity in which context is diminished and a hierarchical neutrality promoted. In turn, this flattening out facilitates a juxtapositioning in which morphological, movement, and abstract values may be foregrounded and new relationships between images and objects revealed. In W. G. Sebald: Image, Archive, Modernity, Long examines this process as follows:

The object is first removed from its cultural, historical, or intersubjective context and made to stand, in metonymic fashion, for a larger abstract whole. It is then subjected to a system of classification so that the ordering of the collection itself overrides the specific histories of the object and its conditions of production and use. The collection erases the labour involved in both producing the object and acquiring it for classification and display. In addition, the collection has the capacity to assign new value to objects that fall within its system. ${ }^{25}$

Though the removal of the contextual features that form All This Can Happen's visual elements is in part a by-product of the cinematographic process (their return being at the discretion of the editor), ${ }^{26}$ the nature of the film's hypermediated approach to presentation suggests a qualitative evaluation predicated on juxtaposition and repetition that is reflective of the archival strategy described above. 
However, despite Long's promise of a new encounter between the now decontextualized images or objects, the capacities for such systems of display are not limitless. Where a pathway for correlation is desired, some cipher is required-a key to enabling the potential for interconnection of the collected materials. If All This Can Happen's mode of presentation is to be perceived as a cabinet of curiosities, it is one in which movement and body, and ultimately acts of walking, provide the themes for its display. Indeed the cabinet metaphor extends to the film's multiple pictorial spaces that mimic the geometric vocabulary of a museum display; the black horizontal and vertical spaces separating each "image field" on screen resembling the physical components of shelving and dividing walls. However, where the physical presentation is by necessity static, All This Can Happen fully avails of the profound malleability of digital video editing. The film continually revises its arrangement of inner windows within the screen's metaframe; each permutation is a new mosaic that enables a diversity of interactions and hierarchies to emerge. A self-reflexive strategy of stilling the moving image and in turn animating the static facilitates a reconsideration of the materials by drawing to the fore their qualities, lingering on relationships, or simply reducing them to archetypes of movement and form. The range of effects is striking and unpredictable, and the ensuing dance of images embraces both the abstract compositional complexities of avant-garde film and the pensive immobility of the photo on screen. ${ }^{27}$ That this display is not subsumed by these combinations and superimpositions, in and of itself choreographically spectacular, is in part due to the specific qualities of the materials and the interconnectivity enabled by their focus on movement and body. However, a further element shapes All This Can Happen; a dramaturgy that imprints upon the visual materials and which in turn enables their complex mode of presentation. Despite the branching divergences and abundance of the archival materials, it is the primacy of Walser's narrated textual through-line that ultimately enables a binding of the film's manifold images into a stable dramaturgy. The organisational logic of the text forces a reconsideration of the visual materials' autonomy and the configuration of a new matrix of connections that disrupts the conventional audio-visual relationship. As previously mentioned, the significance of such interaction between modalities is explored throughout Sebald's work and it is one of Sebald scholarship's central themes. In Sebald, there is a tension between image and text that similarly results in an ambiguous hierarchy that destabilises the usually assumed authority of the photographic archival materials. Deane Blackler examines this as follows:

Although the photographs appear at first to document and illustrate the texts in a conventional fashion, they do so in an artful and playful manner, subverting the reader's habitual expectations of their relationship with the texts as passively illustrative or documentary. They are made to appear to document the texts' "authenticity," inserted by the narrator for his own illustrative or documentary purposes, but I argue that in fact they make 
manifest the fictional game that the author, as distinct from the narrator, is playing with the reader [...] The images, as discursive tools or as the instantiations of memory which Sebald or the "writer" narrator position them to be, are inflected by the fictional context in which they are deployed. ${ }^{28}$

Long provides a further insight into Sebald's relationship to text and image that is particularly informative in this filmic context:

Memory is frequently coupled with the relation between the verbal and the visual. One insight that crops up repeatedly in interviews with the author is that the photograph demands narrativization, making what Sebald terms an "appeal" to the viewer to provide the image with a narrative context, and thereby to rescue it from its nomadic existence. ${ }^{29}$

Sebald's manner of blending fact and fiction is reflected throughout Hinton and Davies' film. Indeed, although the density of interactions between text and image are predictably intensified in the cinematic medium, the text's capacity to stabilize the archival materials is arguably retained. That is not to suggest that the connections between images we see in All This Can Happen are completely smoothed out by the narration we hear but rather that a facilitation of radical and indeed more turbulent organizing structures is enabled by the text's grounding effect. However this facilitation is somewhat complicated by the nature and quality of the archival materials themselves which, by exhibiting all the hallmarks of their time of making, draw attention to their diverse origins. Outside of the directors' developmental influence, artefacts such as film grain and poor resolution, as well as the black-andwhite images, direct attention toward the film material's archival origins. Indeed, the allure and diversity of these artefacts may hinder the text's stabilizing capacity and challenge the viewer to bracket these out in favour of the text's through-line. Like other artworks which construct meaning via the rearrangement of archival materials, such as Gerhard Richter's Atlas ${ }^{30}$ or Aby Warburg's Mnemosyne Atlas, ${ }^{31}$ an understanding must be reached: an embrace of the archival conditions that requires a "seeing-through" of the artefact and an active participation in the generation of the works' dramaturgical potential. In All This Can Happen, when that reduction is successful, the boundary between the fictive and the authentic may be obscured, to be replaced by an operational reversal. This new hierarchy, in which the fictional layer of the text assumes the role of imagined narrative truth, must then relegate the archival visual layer into a supporting role. With some notable exceptions, such as the appearance of iconic images by Étienne-Jules Marey in All This Can Happen, the image can then simultaneously hold its own indexicality whilst shrugging off its contextuality in favour of Walser's The Walk. 
The degree to which All This Can Happen promotes such viewing strategies and highlights the archival and temporal nature of the images may be further deduced by attending to the implementation and ramifications of the sound layer, which interfuses the textual and visual layers and which particularly characterizes All This Can Happen's distinct relationship to archiving as a form of arts practice. With the exception of the seven pieces of incidental music, and unlike the archival footage and Walser's source text, this layer originates from within the film's production environment and is the only material element of the film formed entirely for the purposes of this work. Whilst the visual and textual components are reliant on previously available materials, the unique authorial imprint available within the sound layer enables a particular insight into the work's archival and communicative qualities.

Of course, in many respects the sound layer that has already received our attention is the narration of Walser's text, voiced by actor John Heffernan. Film-sound theorist Chion has given particular attention to the nature of this form of voice-over narration and its ramifications on the viewed image. ${ }^{32}$ His concept of the "Acousmêtre" (an unseen but heard 'acousmatic being') ${ }^{33}$ is useful in articulating the unique qualities that emerge when a bodiless voice is brought into play. In his book The Voice in Cinema, he presents a range of possible scenarios in which this acousmêtre may be positioned with respect to the filmic space; for instance though the voice may not be physically represented on-screen, it may nonetheless coexist within the diegetic reality of a film, such as in The Wizard of Oz. ${ }^{34}$ Alternatively, the acousmêtre may take on the function of an "I-voice" in which specific norms of sonic delivery (a sound without any variation in spatial quality and lacking in reverb) results in a bodiless voice that resonates "in us as if it were our own voice, like a voice in the first person" and that "can't be inscribed in a concrete identifiable space." ${ }^{35}$ These are qualities that mark All This Can Happen's narration. Additionally, as the nature of the archival materials results in a diffuse diegetic reality, no specific location dominates; as such, the acousmêtre is clearly that of the displaced I-voice, residing in a place and time outside that portrayed by the many images. Chion's thoughts on how such a voice impacts what is viewed are of particular interest in their potential to be positioned as events that have unfolded in the past:

The character's voice separates from the body, and returns as an acousmêtre to haunt the past-tense images conjured by its words. The voice speaks from a point where time is suspended.

The French term for the word "voiceover" is "voix-off" [...] and it designates any acousmatic or bodiless voices in a film that tell stories, provide commentary, or evoke the past. Bodiless can mean placed outside a body temporarily, detached from a body that is no longer seen, and set into orbit in the peripheral acousmatic field. These voices know all, remember all, but 
quickly find themselves submerged by the visible and audible past they have called up-that is, in flashback. ${ }^{36}$

If Heffernan's reading of The Walk enables a narrativization of the archival imagery that forms All This Can Happen, it simultaneously highlights their photographic pastness. We are drawn to the narration of Walser's text as emanating from the now, calling up memories and images that appear in a visualized curio cabinet. However, as Chion suggests, the narration does not wholly dictate the reception of these images, nor is it the only component of the sound responsible for how the film's temporal layers are perceived. An additional sonic contribution is that of Chu-Li Shewring's "sounddesign," which provides particularly valuable insights, especially given the inherently silent nature of the archival sources used in All This Can Happen.

The practice of sound-design within cinema usually involves the generation of an audio layer that supports and enhances a film's on-screen activities; these are expected to have a directly corresponding sonic component, and the sound designer is tasked with creating these in accordance with the work's aesthetic goals. Shewring's deviation from such practices may be considered from two perspectives-her approach to synchronisation and her attentiveness to the non-representational specificity of the filmic materials. Whilst Shewring's sound design does not shirk from supporting the realities represented on-screen, sounds and images drift in and out of synchronisation rather than conforming to the tightly knit relationships typical of the sound film. Indeed the very concept of diegetic sound is strained in the context of this work's dense assembly of archival images. As a result, where synchronisation between sound and image does occur, there is always the suspicion that these sonic events are not truly diegetic. In these instances, such as during the "roguishly graceful path" section, ${ }^{37}$ the moments when sound underpins the passing of trains, ${ }^{38}$ or the actions of a shoe-shiner, ${ }^{39}$ the resulting audio-visual union has a theatrical quality, and the assertion that their interactions may be truthful is seldom made. Film theorist and former Sebald student Donnelly describes this sound-image relationship as "plesiochronous" designating it as "a rough, general synchronization that is not a proper matching of unified in-synch sound and image but fits a general soundtrack to particular images." 40 He further notes that "documentary films, a close relative of newsreels, have dealt with plesiochronous relationships between sound and image by nature of their production background as much as their repertoire of accepted aesthetic strategies." ${ }^{41}$

However, though this approach to sound design suggests a prioritization of the film's archival qualities, it is the manner in which Shewring places emphasis on two additional aspects-the specificity of the film's materials and its manner of construction - that ultimately secures this prioritization and establishes a distancing from the film's diegetic activities. In countering filmic immediacy, both aspects diminish what Christiane Voss describes as "the desire for and expectation of a special 
kind of illusion formation in the cinema." ${ }^{42}$ As previously indicated, there is an inherent destabilization of the diegesis due to the film's reliance on the assemblage of materials from a wide variety of sources. It is impossible to establish continuity when the materials themselves invariably undermine its possibility. Similarly, as archival documents from early cinema and photography, the film's materials, by signalling their ontological status as non-fiction and apparently authentic documentation, restrict immediacy further. In part this is due to the black-and-white images that form the majority of the shots. As Richard Misek states in Chromatic Cinema (2010): "Even if it does not overtly mimic old documentary footage, [a] black-and-white still evokes past representations, implying that the image we see is something a camera once saw. Frame-by-frame, black-and-white declares: 'This happened.'"43 However, even where color is included, the images in All This Can Happen exhibit the artefacts of early cinema; the constrained light sensitivity of the film stock, signs of decay, and accretion of hair and dust imparting a patina that unequivocally declares this condition of pastness. The impact of Shewring's sound design in this context lies in its decided embrace of these very errors and in so doing, by highlighting the markings that result from storage and viewing, it engages directly with features of the archive unexamined by Sebald.

First off, it should be noted that whilst noise and crackle sounds are characteristic features of early sound-film, the source footage in All This Can Happen is invariably silent and only rarely does footage with an accompanying sound channel make an appearance (e.g. the boys' whistling). ${ }^{44}$ Therefore, the many sounds that appear to mimic the hiss and crackle artefacts of early sound-film must be considered as deliberate inclusions rather than unavoidable features. There are two possible objectives that such sound design suggests. The first stems from a simple desire to infuse any imagery with a sense of authenticity by ensuring that the archival footage is accompanied by sound artefacts that mimic those of early cinema and audio recording. This is a familiar strategy in film-sound, and may be considered alongside a general romanticization of analogue-era technologies as evidenced by the practice of adding vinyl record sounds onto digital music recordings (artificial errors). Importantly, this approach assumes that such sounds will be considered unconsciously, relegated into the background as a texture that does not require particular attention. Sounds listened to in this passive way may function to provide context (the background hum of a city) or enable a general qualitative sensibility toward those elements which do contend for our attention, in this instance providing a sense of the medium's fragility and age. ${ }^{45}$ When sound is used in this way, its components are not presented as imparting specific meaning; the city's soundscape does not consist of specific cars or sirens but consists instead of a collective of such sounds that only together provide the necessary descriptive sonic backdrop. Similarly, the inherent noises of the gramophone medium are perceived not as individual rumbles and clicks but instead as a continuous stream of sounds that collectively reveal the fragile nature of their 
medium. However, a very different perceptual and aesthetic outcome occurs when the sound designer decisively draws our attention to the specific qualities of individual sounds that might normally be considered part of the sonic backdrop. In this alternative sound design strategy, the objective in foregrounding such sounds introduces the possibility of their being considered as deliberate compositional elements. Those clicks and rumbles become part of a musical language, their rhythms and repetitions building tension or providing momentum. To suggest that this second objective may be at play in the film's sonic embrace of media "failures" would imply a more radical aesthetic embrace of the artefact in All This Can Happen. One may identify that this is indeed the case by attending to the specific interactions that occur between the visual artefacts of filmic decay and the sound design. Here, deliberate and precise sounds that mimic these artefacts synchronously respond to similar onscreen failures and, rather than providing a corresponding homogenous sonic counterpoint, foreground their contribution through radically alternating sonic textures that do not promote a passive listening approach. In short: the sound design becomes a foregrounded feature akin to that of music and language, and in so doing, it highlights the conditions of media decay and media failure as one of the film's primary thematic concerns.

In 2000, the Computer Music Journal published an article by composer Kim Cascone titled "The Aesthetics of Failure" that resonated with an emerging embrace of the digital artefact's potential. ${ }^{46}$ This trend was not limited to music but was equally evident within the visual arts. Cascone's insights proved to be the primary stimulus for a field of practice and enquiry focussed on the digital glitch and, by extension, its art historical precedents. In "Aesthetics of the Error: Media Art, the Machine, the Unforeseen, and the Errant," Tim Barker expresses how "the potential for error marks the potential for the new and the unforeseen [...] an error in itself may be creative. An error may be utilized. It may be sought out and used to create the unforeseen within traditional systems, such as routine computer use, musical compositions, or visual art practice. ${ }^{\prime \prime 7}$ In All This Can Happen, dust, scratches, and film-noise unite the displays of human movement, a through-line of textures and patterns that, when rendered sonically, perform their own dance within and between the progression of images. And whilst the film's position within this aesthetic movement is in itself significant, this embrace of the artefact further serves to integrate by-products of the archival process as central aesthetic features. With this expressive potential privileged, the fragility of the archive is brought into focus; decay declares its pastness. In the above article, Barker further describes a work by Yann Le Guennec titled Le Catalogue, which resonates strongly with All This Can Happen:

This Internet-based work allows public access to a catalogue of images and installations created between 1990 and 1996. Every time a page is accessed from the archive, an intended error is activated in the form of an intersecting horizontal and vertical line, generated at random points over 
the image. The more that the page is viewed, the greater its deterioration by the obscuring intersecting lines and the closer the image comes to abstraction. As Eduardo Navas states, "the archive is similar to analogue vinyl records losing their fidelity and being slightly deteriorated every time the needle passes through the groove." In Le Guennec's catalogue the act of accessing and consulting the information of the archive in essence causes an internal error to the information. This is an error that is inbuilt; it is an error that we cause by the act of looking at or accessing any of the images. ${ }^{48}$

Within Sebald's works and the film All This Can Happen, the role of the archive, as model and material, permeates throughout. For both, the interplay between text and image is a central narrative mechanism, and whilst the operational systems of book and film are distinct, there is little doubt that kindred philosophies inform their formative perceptual assumptions. However, the nature of Sebald's authorship of both text and (in many instances) the images, enables a degree of integration unavailable in All This Can Happen. Walser's The Walk, albeit adapted and narrated, retains its original design as a monomodal text when integrated into the filmic context. What is of interest is the degree to which that design is agitated or bolstered by this new context. As mentioned at this article's outset, The Walk is a text fixed upon the present moment; each paragraph's achievement is to render the preceding one inconsequential, whereupon it is in turn replaced by yet another. Yet its new filmic context initially appears to counter this temporal inclination by means of imagery and presentation methods that do not promote an immediate viewing that is similarly erasive. Instead, hypermediacy and the foregrounding of artefacts supplement the inherent signs of the archival images to create a visual world that repeatedly declares "I was" (distinct from Walser's "I am"). If Sebald accommodates the product of such media effects within a similarly oriented narrative, then Hinton and Davies' integration must either resign itself to a functional dissonance (Walser's textual immediacy versus the film's photographic hypermediacy) or endeavour to find a harmonizing strategy between these contrasting elements. Of course one might simply claim that the thematic bond between text and film adequately reconciles these temporal orientations; that the archival imagery's faithful rendering of Walser's text suppresses any impression of disparity. Yet this assumption presents the text as a dominant modality and similarly assumes a preference for an integration of text, image, and sound that is functionally uniform. Perhaps this is not the case. Defiant of immersive mechanisms, the film's favouring of hypermediacy, overt employment of archival materials, and its foregrounding of artefact may promote a variable arrangement directed by the viewer in which Walser's text does not necessarily monopolise. Whilst the interplay between text, image, and sound is compelling, it is not constrained to a single viewing strategy. Indeed, the ephemerality of The Walk's unfolding subjects, its curious dramatic indeterminacy, facilitates-indeed promotes-an ebb and flow of 
attention in which the text is brought in and out of focus. The sound layer is similarly receptive to such open viewing strategies; and by privileging in turn the textual, archival, and qualitative layers, it marks out the diversity of reading modes available throughout the film. In this way, All This Can Happen subverts dramatic expectations, inverting the notion of textual adaptation and replacing it with a dynamic landscape of pathways in which fiction, archive, and medium interweave, each beckoning for our attention.

\section{Biography}

Jürgen Simpson is director of the Digital Media and Arts Research Centre at University of Limerick and the co-curator of Light Moves Festival of Screendance. His work spans the areas of dance, electronic music, film, opera, and installation art. In the area of dance, collaborators include choreographers John Scott and Shobana Jeyasingh, composer Michael Nyman, and seven screendance works with director Mary Wycherley. Metamorphosis, with director Clare Langan, received the principal award at the 2007 Oberhausen Film Festival. Operatic works include Air India: Redacted, premiered in Vancouver in 2015, and Thwaite, which received the Genesis Opera Project's top award in 2003. Recent writing includes a chapter in the Oxford Screendance Handbook.

Email: jurgen.simpson@ul.ie

\section{Notes}

${ }^{1}$ Davies and Hinton, "All This Can Happen"

${ }^{2}$ Galchen, "From the Pencil Zone: Robert Walser's Masterworklets," and Walser, Der Spaziergang, 3.

${ }^{3}$ Benjamin, 351.

${ }^{4}$ Ibid., trans. Andrea Scrima. "The Walk by Robert Walser: Reviewed by Andrea Scrima." Posted 23 July 2012. http://therumpus.net/2012/07/the-walk-by-robert-walser/

${ }^{5}$ Coetzee, "Heir of a Dark History."

${ }^{6}$ Sontag, "A Mind in Mourning."

7 Sebald, Logis in Einem Landhaus.

${ }^{8}$ de Duve, 52.

${ }^{9}$ Sontag, On Photography. 70. 
${ }^{10}$ Barthes, Camera Lucida.

${ }^{11}$ Barthes, Camera Lucida.

${ }^{12}$ Barthes, Camera Lucida and Mulvey, Death 24x a Second. 66.

${ }^{13}$ Bolter and Grusin, 23.

${ }^{14}$ Ibid., 11.

${ }^{15}$ Barthes, 89, 90.

${ }^{16}$ Bolter and Grusin, 33.

${ }^{17}$ Streitberger and van Gelder, 51.

18 Ibid., 48.

${ }^{19}$ Mulvey, 191.

${ }^{20}$ Long, 19, 35.

${ }^{21}$ Bolter and Grusin, 31.

22 Ibid., 33.

${ }^{23}$ Long, 28.

${ }^{24}$ Kraenzle, 130.

${ }^{25}$ Kraenzle, 130.

${ }^{26}$ Bazin, "Death Every Afternoon," 27-31.

27 de Duve, "Time Exposure and Snapshot: The Photograph as Paradox."

${ }^{28}$ Blackler, 138.

${ }^{29}$ Long, 47.

30 "Gerhard Richter's Atlas is one of several structurally similar yet rather different projects undertaken by a number of European artists from the early to mid 1960s whose formal procedures of accumulating found or intentionally produced photographs in more or less regular grid formations (one could think of the forty-yearlong collection of typologies of industrial architect Bernhard and Hilla Becher begun in 1958, or the work of Christian Boltanski begun in the late 1960s) have remained strangely enigmatic." (Buchloh, "Gerhard Richter's 'Atlas,'" 117)

31 "Begun in 1924 and left unfinished at the time of his death in 1929, the Mnemosyne Atlas is Aby Warburg's attempt to map the 'afterlife of antiquity,' or how images of great symbolic, intellectual, and emotional power emerge in Western antiquity and then reappear and are reanimated in the art and cosmology of later times and places, from Alexandrian Greece to Weimar Germany [... ] In its 'last version,' the Mnemosyne Atlas consisted of sixty-three panels (Tafeln). Using wooden boards, measuring approximately $150 \times 200 \mathrm{~cm}$ and covered with black cloth, Warburg arranged and rearranged, in a lengthy combinatory process of addition and subtraction, black and white photographs of art-historical and cosmographical images. Here and there he also included photographs of maps, manuscript pages, and contemporary images drawn from newspapers and magazines. The individual panels, in turn, were then numbered and ordered to create still larger thematic sequences." (Johnson, "About the Mnemosyne Atlas.")

${ }^{32}$ Chion, The Voice in Cinema. 
33 "The French term is a neologism made from 'être acousmatique,' or acousmatic being." (Chion, The Voice in Cinema, 49). Acousmatic refers to a sound that is heard but cannot be seen.

${ }^{34}$ Fleming, The Wizard of Oz.

${ }^{35}$ Chion, The Voice in Cinema, 51.

${ }^{36}$ Ibid., 49.

${ }^{37}$ All This Can Happen, 17:25 - 18:49.

${ }^{38}$ Ibid., 07:17 - 07:25.

${ }^{39}$ Ibid., 38:10 - 38:38.

${ }^{40}$ Donnelly, 182.

${ }^{41}$ Ibid., 182.

${ }^{42}$ Voss, 138.

${ }^{43}$ Misek, 92.

${ }^{44}$ All This Can Happen., 41:40 - 42:08.

${ }^{45}$ Kane, 27 and Demers, 148.

${ }^{46}$ Cascone, "The Aesthetics of Failure."

${ }^{47}$ Barker, 56.

${ }^{48}$ Ibid., 53.

\section{References}

All This Can Happen. Dir. Siobhan Davies and David Hinton. UK, 2012. ProRes422.

Barker, Tim. "Aesthetics of the Error: Media Art, the Machine, the Unforeseen, and the Errant." Error: Glitch, Noise, and Jam in New Media Cultures. Ed. M. Nunes. New York: Continuum Books, 2011.

Barthes, Roland. Camera Lucida. Trans. R. Howard. New York: Hill and Wang. 2010.

Barzilai, Maya. "On Exposure: Photography and Uncanny Memory in W.G. Sebald's Die Ausgewanderten and Austerlitz." W. G. Sebald and the Writing of History. Ed. S. Denham, Irene Kacandes, and Jonathan Petropoulos, Berlin: Walter de Gruyter, 2006.

Bazin, André. "Death Every Afternoon." Rites of Realism: Essays on Corporeal Cinema. Trans. M. Cohen. Ed. I. Margulies, Durham: Duke University Press 2003.

https://doi.org/10.1215/9780822384618-003 .What Is Cinema? Trans. H. Gray. Berkeley: University of California Press, 2005.

Benjamin, Walter. "Robert Walser." Illuminationen: Ausgewählte Schriften. Frankfurt am Main: Suhrkamp Verlag, 1977. 
Blackler, Deane. Reading W. G. Sebald. New York: Camden House, 2007.

Bolter, Jay David \& Grusin, Richard. Remediation: Understanding New Media. Cambridge, Mass.: MIT Press, 2000.

Buchloh, Benjamin H. D. "Gerhard Richter's 'Atlas': The Anomic Archive." October, 88.2 (Spring 1999): 117-145.

Cascone, Kim. "The Aesthetics of Failure: 'Post-Digital' Tendencies in Contemporary Computer Music" Computer Music Journal 24.4 (Winter 2002): 392-398.

Chion, Michel. The Voice in Cinema. Trans. C. Gorbman. New York: Columbia University Press, 1999.

Coetzee, John M. "Heir of a Dark History." The New York Review of Books 49.16 (October 24, 2002): 25.

de Duve, Thierry. "Time Exposure and Snapshot: The Photograph as Paradox." The Cinematic. Ed. David Campany. London/Cambridge, Mass.: Whitechapel and MIT Press, 2007.

Demers, Joanna. "Discursive Accents in Some Recent Digital Media Works." The Oxford Handbook of Sound and Image in Digital Media, Ed. C. Vernallis, Amy Herzog, and John Richardson. Oxford University Press, 2014.

Donnelly, Kevin J. Occult Aesthetics: Synchronisation in Sound Film. New York: Oxford University Press, 2014. https://doi.org/10.1093/acprof:oso/9780199773497.001.0001

Galchen, Rivka, 2010. "From the Pencil Zone: Robert Walser's Masterworklets." Harpers Magazine (May 2010): 73-78.

Johnson, Christopher D. "About the Mnemosyne Atlas." Mnemosyne: Meanderings through Aby Warburg's Atlas. Accessed Sept. 2016.

http://warburg.library.cornell.edu/about

Kane, Brian. Sound Unseen: Acousmatic Sound in Theory and Practice. New York: Oxford University Press, 2014. https://doi.org/10.1093/acprof:oso/9780199347841.001.0001

Kraenzle, Christina. "Picture Place: Travel, Photography, and Imaginative Geography in W.G. Sebald's Rings of Saturn." Searching for Sebald: Photography After W.G. Sebald. Ed. Lise Patt \& Christel Dillbohner. Los Angeles: Institute Cultural Inquiry, 2007.

Long, J.J. W. G. Sebald: Image, Archive, Modernity. Edinburgh: Edinburgh University Press. 2007. https://doi.org/10.3366/edinburgh/9780748633876.001.0001 
Misek, Richard. Chromatic Cinema. Oxford: Wiley-Blackwell, 2010. https://doi.org/10.1002/9781444320077

Mulvey, Laura. Death 24x a Second. London: Reaktion Books, 2006.

Sebald, W.G. Logis in Einem Landhaus: Uber Gottfried Keller, Johann Peter Hebel, Robert Walser, und Andere. Munich: Carl Hanser Verlag, 1998.

Sontag, Susan. "A Mind in Mourning." The Times Literary Supplement (February 25, 2000).

. On Photography. New York: Penguin, 1977. https://doi.org/10.1386/pop.1.1.48/7

Streitberger, Alexander and van Gelder, Hilde. "Photo-filmic images in contemporary visual culture." Philosophy of Photography 1.1 (2010): 48-53.

http://dx.doi.org/10.1386/pop.1.1.48/7

Voss, Christiane. "Film Experience and the Formation of Illusion: The Spectator as 'Surrogate Body' for the Cinema." Cinema Journal, 50.4. (Summer 2011):136-150. Trans. Inga Pollmann. https://doi.org/10.1353/cj.2011.0052

Walser, Robert. Der Spaziergang. Frankfurt am Main: Suhrkamp Verlag, 1978.

The Wizard of Oz. Dir. Fleming, Victor. Prod. Metro-Goldwyn-Mayer. 1939. Film. 